\title{
rommhalina
}

(8)

\section{Camões e(m) Garret}
Autor(es): $\quad$ Berardinneli, Cleonice
Publicado por: Imprensa da Universidade de Coimbra
URL persistente:
URI:http://hdl.handle.net/10316.2/31214
DOI:
DOI:http://dx.doi.org/10.14195/978-989-26-0569-2_38

Accessed : $\quad$ 26-Apr-2023 13:38:36

A navegação consulta e descarregamento dos títulos inseridos nas Bibliotecas Digitais UC Digitalis, UC Pombalina e UC Impactum, pressupõem a aceitação plena e sem reservas dos Termos e Condições de Uso destas Bibliotecas Digitais, disponíveis em https://digitalis.uc.pt/pt-pt/termos.

Conforme exposto nos referidos Termos e Condições de Uso, o descarregamento de títulos de acesso restrito requer uma licença válida de autorização devendo o utilizador aceder ao(s) documento(s) a partir de um endereço de IP da instituição detentora da supramencionada licença.

Ao utilizador é apenas permitido o descarregamento para uso pessoal, pelo que o emprego do(s) título(s) descarregado(s) para outro fim, designadamente comercial, carece de autorização do respetivo autor ou editor da obra.

Na medida em que todas as obras da UC Digitalis se encontram protegidas pelo Código do Direito de Autor e Direitos Conexos e demais legislação aplicável, toda a cópia, parcial ou total, deste documento, nos casos em que é legalmente admitida, deverá conter ou fazer-se acompanhar por este aviso. 


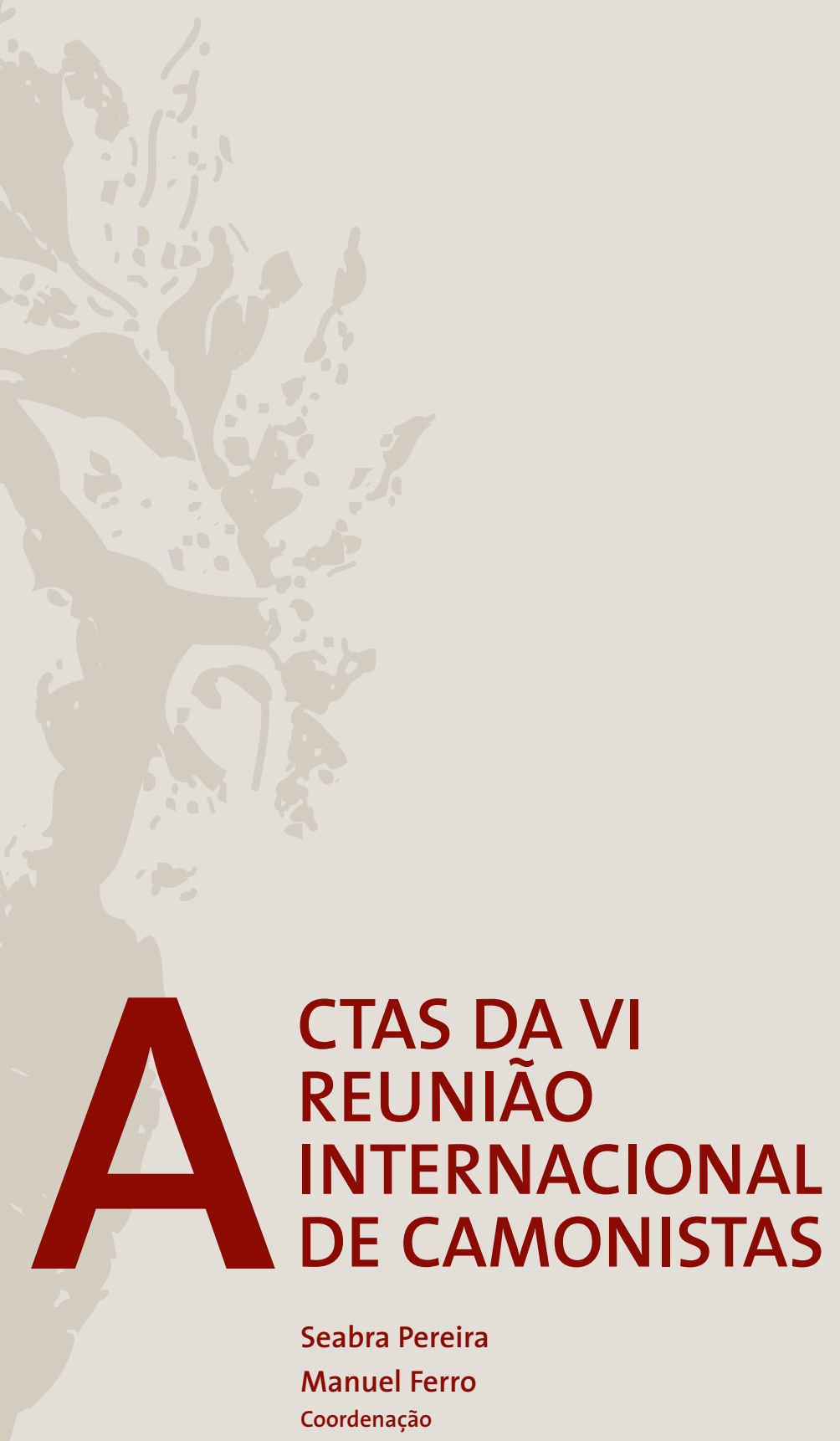




\section{Cleonice Berardinneli}

UFRJ / PUC-Rio de Janeiro

\section{CAMÓES E(M) GARRET}

Nascido em fevereiro de 1799, Garrett tinha apenas 21 anos quando a força armada sediada no Porto "justamente e com toda a legitimidade fez e protegeu a feliz revolução do dia 24 de Agosto” (são palavras suas). A eclosão do movimento de 1820 será saudada pelo jovem acadêmico da Universidade de Coimbra num texto que endereça ao Congresso Nacional no ano seguinte, para ele o Ano I de uma nova era em Portugal ${ }^{1}$ : a era da justiça, da liberdade, da igualdade. Vale a pena ler algo da sua dedicatória ao mesmo tempo lúcida e apaixonada, dignificante e repassada de uma certa pretensão juvenil; assim começa ele:

Aos pais da Pátria ofereço a defesa da causa dela. Os verdadeiros portugueses não carecem das poucas luzes deste escrito para conhecerem a justiça, com que o heroísmo de poucos homens os libertou do jugo de tantos: os sentimentos de liberdade, e valor nasceram com eles. [...] Mas nem só a Portugueses me dirijo: eu falo à Europa, e ao mundo falo com intrepidez, porque falo a simples verdade. $^{2}$

Dirige-se em seguida "Aos Leitores", enumerando as etapas da felicidade que assaltou os verdadeiros Portugueses ao experimentar "o prazer súbito do maior dos bens", a Liberdade; do "santo furor" haviam passado a um entusiasmo "mais sólido" e prudente, evitando a todo custo "lavar as aras da Liberdade com o sangue vil"3. E, revelando desde já o que será um vezo seu ao longo de sua produção literária, faz anteceder o texto propriamente dito de um terceiro paratexto: "Introduçáo", iniciada por um breve período: "Já temos uma Pátria, que nos havia roubado o despotismo." Adiante, acrescenta: "o sol da liberdade brilhou no nosso horizonte, e as derradeiras trevas do despotismo foram, dissipadas por seus raios, sepultar-se no Inferno." Mais à frente, recorrendo a tom oratório bastante persuasivo, a interpelar o leitor / ouvinte

\footnotetext{
${ }^{1}$ Almeida GARRETT, Obras de ... Porto, Lello \& Irmão, 1963, v. I, p. 1043.

${ }^{2}$ Ibidem, p. 1045.

3 Ibidem, p. 1047.
} 
e a responder-lhe, lembra os verdadeiros portugueses do passado, aqueles mesmos, paradigmáticos, que estão n’ Os Lusíadas:

Qual era dentre nós, que se não pudesse chamar oprimido? Qual há dentre nós, que se não possa chamar libertado? Qual foi o Português que não gemeu, que não chorou ao som dos ferros? Qual é o Português que não folgará com a liberdade? Nenhum por certo: os netos de Moniz, de Nun'Álvares, de Gama, de Castro, de Pacheco, são o que sempre foram - Portugueses. ${ }^{4}$

Entrando, finalmente, no texto, afirma: "Os homens são iguais porque são livres; e são livres porque são iguais.” e prossegue, corajosamente apontando erros e vícios morais, causadores da corrupçáo dos costumes, para concluir que "o governo de Portugal até ao dia 24 de Agosto era tirânico, despótico e injusto”.

No ano anterior, para festejar o nascimento de uma princesa, Garrett se dispusera a escrever um "elogio dramático" intitulado "O amor da Pátria", que ficou inacabado. A peça tem como "lugar da cena" "Os Elísios", espaço sem tempo, o que permite a presença simultânea de personagens de épocas diversas: dois reis - D. João II e D. Dinis -, aquele que foi a maior figura da história de Portugal no Oriente - Afonso de Albuquerque -, Camóes e a deusa da sabedoria - Minerva -, que os levou ao "templo sacrossanto", chamando-lhes "Dinis excelso, / Extremado João, vate sublime, / Guerreiro ilustre”. O fragmento dramático é ainda imaturo, mas nos breves dezassete versos da fala de Camóes a D. João II ressoa a sua voz de sujeito lírico dos excursos d' Os Lusíadas, a reiterar a consciência do valor do seu canto e o seu extremo amor à pátria, pátria ingrata que não o soube reconhecer, mas de que ele diz: "um só momento / Nunca deixei de amar, adoro-a ainda”. No poema épico, pela voz de Vasco da Gama, o Poeta sintetizara a caracterização do rei, em quatro versos impecáveis:

Este, por haver fama sempiterna,

Mais do que tentar pode homem terreno,

Tentou, que foi buscar da roxa Aurora

Os términos que eu vou buscando agora. ${ }^{5}$

No poema de um Garrett ainda incipiente, é o próprio Camôes que ressalta o valor do rei, sem o deixar esquecer que, se "nos fastos" da "Europa e da Terra" seu nome "vive, e brilha", é porque, como diz sem disfarce, "Meu canto o consagrou à eternidade; / Pela voz da razão clama ao universo / Que ensinaste a ser reis os reis do mundo."

Se deixarmos de parte um soneto da extrema juventude, intitulado "Camóes náufrago", acredito que este texto, embora incompleto, tenha sido o primeiro em que Garrett trouxe com certa força, para a cena, o poeta que admira e quer celebrar em sua condiçáo de artista máximo e homem sensível, magoado por não ter recebido da pátria "o favor com que mais se acende o engenho".

\footnotetext{
${ }^{4}$ Ibidem, p. 1049.

${ }^{5}$ Luís de CAMÓES, Os Lusiadas. Comentados por Augusto Epipphanio da Silva Dias, 2. Ed. Melhorada, Porto, Companhia Portugueza Editora, 1916, Canto IV, estr. 60.
} 
Antes mesmo de escrever $O$ amor da Pátria, já estava Garrett rascunhando o seu Bosquejo da história da poesia e língua portuguesa; é o que ele diz na sua "Advertência", escrita quase aos vinte e dois: "tanto o poema como as notas e o ensaio são da minha infância poética; são compostos na idade de dezassete anos.” Data, pois, dos seus bem verdes anos a admiraçáo que nutre pelo poeta que

... foi para tâo longe da ingratíssima pátria despicar-se de seu desamor com a mais nobre vingança: a de levantar-lhe um padrão, com que não entram as idades, e que conservará ainda o nome português quando já ele houver desaparecido da Terra. ${ }^{6}$

Louva sua "erudição (pois sabia quanto se soube em seu tempo) [e] engenho dos que vêm ao mundo de séculos a séculos"; considera todos os outros poetas pigmeus perante aquele que

... abri[u] um caminho novo, cri[ou] a poesia moderna, d[eu] não só a Portugal, mas à Europa toda um grande exemplo, e constitui[u]-se o Homero das línguas vivas. $^{7}$

Mas será depois de 1823, já exilado no Havre, que começará a escrever o seu primeiro texto longo e bem realizado, que ele qualifica como "obrita" em carta a seu amigo Duarte Lessa, acrescentando:

A obra é um poema em 10 cantos, cujo título e assunto é - Camóes -. Suas aventuras e suas composições formam o fundo histórico; mas Os Lusíadas ocupam a cena... - A acção é a composição d'Os Lusíadas - e portanto grande parte do meu poema uma análise poética dele. ${ }^{8}$

Terá totalmente razão o autor na caracterização que faz do seu poema? Não me parece. Talvez concorde com o que ele considera o fundo histórico, mas não com ser a ação a composição d' Os Lusíadas. Começo por hesitar entre os dois sentidos básicos da palavra composiçâo, o dinâmico ou o estático: o acto de compor ou o seu efeito? De qual deles diz Garrett que faz a análise poética? Não a vejo, nem de um, nem de outro. Haverá, isso sim, a valorização da epopeia e do seu autor: deste, através do seu comportamento, das suas atitudes, dos julgamentos feitos pelo narrador do poema oitocentista; daquela, através da citação, da paráfrase e do pastiche, como já observou, e muito bem, Carlos Reis. Na carta há pouco citada, de Julho de 1824, Garrett expóe ao amigo como compôs o Camóes, muito conscientemente:

Dei-lhe um tom e um ar de romance para interessar os menos curiosos de letras, e geralmente falando o estilo vai moldado ao de Byron e Scott (ainda

\footnotetext{
${ }^{6}$ Almeida GARRETT, Op. Cit., v. I, p. 492.

${ }^{7}$ Ibidem, p. 492-3.

${ }^{8}$ Ibidem, p. 1382.
} 
não usado nem conhecido em Portugal) mas não servilmente e com macacaria, porque sobretudo quis fazer uma obra nacional. [...] Porventura me criticarão a novidade de fazer um poema assunto de outro: sei que sou o primeiro que me atrevo a isso [...]"?

Esta inovação lhe agrada, e tanto, que mais tarde porá em Um auto de Gil Vicente a representaçáo das Cortes de Júpiter, com suas figuras e alguns de seus versos, trazendo à cena, para o momento em que faz renascer o teatro português, o dramaturgo que "abriu os fundamentos ao teatro das línguas vivas”. Mas não é tudo: também é personagem das Cortes Bernardim Ribeiro (enxertado pela criação garrettiana que se fundamenta em lendas que correm sobre o autor mais "romântico" do quinhentismo), definido no Bosquejo como aquele a quem "o que lhe falta em sublime e culto sobeja-lhe em brandura, e numa ingénua ternura que faz suspirar de saudade." Não tão inovador era o jovem autor em "fazer um poema assunto de outro", pois que, no teatro, tinha pelo menos três antecessores no século XVI, que faziam de um auto assunto de outro: Gil Vicente, no Auto da Lusitânia, o Chiado, no Auto da Natural Invenção, e o próprio Camóes, no Auto de El-Rei Seleuco. O jogo da intertextualidade é bem antigo na literatura portuguesa...

Por que trazer Camóes para o presente, fazendo-o protagonista de uma história triste num poema que tem "um tom e um ar de romance", história triste de um homem-cidadão-poeta, frustrado em seus três amores: Natércia está morta; a pátria, por quem lutou, que tanto ama, "mãe descaroável", o enjeitou; o poema, acolhido com entusiasmo por D. Sebastiáo, que lhe promete fazer mercê, será esquecido "no apreste / Da jornada fatal" que ocupava todo o "malfadado moço que em sua cólera / Rei dera o céu ao povo lusitano”? A pergunta é meramente retórica, já que a resposta, todos a sabem: pela projeçáo do retratado no retratador, ambos amantes da pátria, ambos exilados, ambos poetas, enfrentando a dificuldade de imprimir-se. Só a frustração amorosa ainda não os aproximava; viria mais tarde para Garrett. Pelo desejo de reviver um momento histórico em descida, que tanto se assemelhava ao que vivia, e ao mesmo tempo de recuperar as glórias celebradas no poema épico, tentando injetar sangue vivo dos heróis do passado nas veias ressequidas dos homens do presente. Em excelente ensaio sobre "Intertextualidade e ideologia: uma imagem romântica de Camóes”, Carlos Reis quase náo nos deixa matéria a explorar, tal a acuidade e detença com que trata de cada ponto levantado no poema. Retomo, pois, algumas afirmaçóes suas sobre a relação arquitextual entre o Camóes e Os Lusíadas, e que contribuem, sem que o explicite, para o reconhecimento da qualidade literária do poema romântico:

... Garrett pretende tacitamente vincar que o cânone perfilhado não constitui uma norma rígida, mas uma directriz de criação estética susceptível de consentir a margem de originalidade que ajuste o poema a circunstâncias históricas e ideológicas naturalmente diversas das que caracterizam a epopeia camoniana;

\footnotetext{
9 Ibidem.
} 
[...] a inflexibilidade de um modelo atentaria contra a liberdade criativa que a viragem para o Romantismo começava a conquistar de modo irreversível. ${ }^{10}$

Teria interesse aproximar dessas palavras do ensaísta contemporâneo as do crítico neoclássico José de Urcullu, que, em carta a Duarte Lessa, queixa-se da falta de unidade do poema, diante do qual se sente como quem fita um quadro formoso, mas não percebe o que o artista quis expressar. Náo entende a invocaçáo inicial à Saudade, acha-a mais que dispensável, danosa à clareza do poema, já que "de esta falta de exposición nace la oscuridad que reyna en todo el canto" ${ }^{11}$. Preferiria que, em vez de transformar a Saudade em deidade, Garrett tivesse invocado a sombra de Camóes, ou sua divina pena, ou mesmo a "Pátria". Critica ainda a passagem de tom, do sublime ao familiar e ainda o não se saber, até ao terceiro canto, quem é o herói do poema. A recepçáo de Urcullu padecia do facto de estar ele ainda preso ao classicismo arcádico, mas também de uma boa dose de insensibilidade para o fenómeno poético. A presença da Saudade à entrada do poema, naquele lugar destinado à(s) Musa(s), nomeada(s) ou não, desde Homero, passando por Virgílio, é dos mais felizes achados do poeta, que será, desde então, romântico, embora não queira confessá-lo. Para Carlos Reis,

A primeira impressão que se colhe, desde a primeira leitura da estrofe transcrita, é a do carácter vernáculo do léxico, capaz de evocar uma atmosfera cultural classicista: vocábulos como "pungir", "misérrimo", "inda" e "ovante", associados ao latinismo "númen" várias vezes repetido, valem sobretudo pelas conotaçóes que os envolvem, as quais remetem a uma espécie de linguagem-matriz que é a do discurso camoniano. ${ }^{12}$

Para mim, apesar do léxico (do qual não encontro n' Os Lusíadas nem "pungir", nem "númen"), o que o texto cria em mim é o clima de melancolia, isolamento, exílio, em suma, saudade. Dificilmente poderia dizer que esta é ou foi a minha primeira impressão, hoje tão distanciada de mim como a felicidade do menino pessoano que se pergunta: "E eu era feliz?" para responder-se: "Fui-o outrora agora." Agora - e creio que desde sempre - o que me fica é muito mais a emoção criada pela presença insistente da Saudade do que pela camada significante através da qual esta é expressa. E é esta Saudade, sinalizando à entrada do poema, que lhe dá o tom, como diapasáo usado para que se afinem os instrumentos e as vozes. Talvez porque assim penso é que divirjo algum tanto da posição do meu colega e amigo Carlos Reis, quando, falando da transição do intertexto à ideologia - e nisto estamos de acordo! -, diz:

${ }^{10}$ Carlos REIS, Construção da leitura, Coimbra, Instituto Nacional de Investigação Científica / Centro de Literatura Portuguesa da Universidade de Coimbra, 1982, p. 67.

${ }^{11}$ Ofélia M. C. MONTEIRO, A formação de Almeida Garrett, Coimbra, Centro de Estudos Românicos, v. 11,1971 , p. 167.

12 Carlos REIS, Op. Cit., p. 71. 
... é ao serviço dessa afirmação ideológica que naturalmente se encontram as linhas de força do herói representado na epopeia, bem como as relaçóes intertextuais que ele inspira. ${ }^{13}$

A pequena dúvida que tenho, em decorrência do que acabo de pôr em causa, origina-se em se considerar que as "linhas de força" do herói estão "ao serviço da afirmação ideológica”; sinto-as como também nesta função, mas sobretudo na caracterizaçáo do herói como o poeta satúrnio, marcado por "estrelas infelices" às quais não pode escapar, pois "com ter livre alvedrio, mo náo deram, / que eu conheci mil vezes na ventura / o milhor, e o pior segui, forçado.” É o poeta máximo que assim se define na Canção X, à qual tomo versos finais, parodiando: "no mais; que irei falando / sem o sentir, mil anos." Haveria tanto a dizer desses dois poetas cujos fios tantas vezes se entrecruzam, puxados pelos dedos sábios e reverentes do mais novo, a criar um novo texto, de cuja qualidade estética não há como duvidar ${ }^{14}$. O poema Camóes acompanha os dias finais do épico e de seu país: "Pátria, ao menos / Juntos morremos... E expirou com a pátria."

Antes, porém, ele exprimira um desejo:

Soberbo Tejo, nem padrão ao menos

Ficará de tua glória? Nem herdeiro

De teu renome?... Sim: recebe-o, guarda-o,

Generoso Amazonas, o legado

De honra, de fama e brio: não se acabe

A língua, o nome português na terra. ${ }^{15}$

Há mais de cinquenta anos recebi o legado e venho lutando para que se mantenha e divulgue a língua e a cultura de Portugal na terra do Amazonas generoso.

13 Ibidem, p. 72.

${ }^{14}$ Almeida GARRETT, Camões. Apresentação crítica, notas e sugestôes para análise literária de Teresa Sousa de Almeida, Col. “Textos Literários”, Lisboa, Editorial Comunicação, 1986, p. 14.

${ }^{15}$ Luís de Camôes, Op. Cit., Canto X, estr. 21. 